\section{丽 Heighten Science \\ P U B L I C I T T I O N S Corporation} ISSN 2575-0143
*Address for Correspondence: Ylber Jani, MD, $\mathrm{PhD}$, Faculty of Medicine, Tetovo, Republic of North Macedonia, Tel: 0038976241830 ;

Email: ylber_jani@hotmail.com

Submitted: 17 June 2019

Approved: 26 June 2019

Published: 27 June 2019

Copyright: (c) 2019 Jani Y, et al. This is an open access article distributed under the Creative Commons Attribution License, which permits unrestricted use, distribution, and reproduction in any medium, provided the original work is properly cited

Keywords: C-reactive protein; QTC-dispersion; Tpeac-Tend dispersion in patient with metabolic syndrome

Abbreviations: MetS: Metabolic Syndrome; CRP: C-reactive protein; BW: Body Weight; BH: Body Height; BMI: Body Mass Index; BP: Blood Pressure; SBP: Systolic Blood Pressure; DBP: Diastolic Blood Pressure; T2DM: Diabetes Mellitus type 2; WCi: Waist Circumference; QTC: Corrected QT-Interval; Tpeac-Tend-Tpeac: Tend Interval; APD: Action Potencial Duration; HDL-C: High Density Lipoproteins Cholesterol; TG: Serum Triglycerides; ESC: European Society of Cardiology

Check for updates

\title{
C-reactive protein is associated with ventricular repolarization dispersion among patients with metabolic syndrome
}

\author{
Ylber Jani ${ }^{*}$, Atila Rexhepi ${ }^{2}$, Bekim Pocesta ${ }^{3}$, Ahmet Kamberi, \\ Fatmir Ferati ${ }^{5}$, Sotiraq Xhunga ${ }^{6}$, Artur Serani ${ }^{7}$, Dali Lala ${ }^{8}$, Agim $^{2}$ \\ Zeqiri' and Arben Mirto ${ }^{10}$ \\ ${ }^{1}$ Faculty of Medicine, Tetovo Republic of North Macedonia \\ ${ }^{2}$ Department of Internal Medicine, Faculty of Medicine, Tetovo, Republic of North Macedonia \\ ${ }^{3}$ Department of Cardiology, Faculty of Medicine, Saints Cyril and Methodius University of Skopje, Republic of \\ North Macedonia \\ ${ }^{4}$ Department of Cardiology, Faculty of Medicine, M Teresa, Tirana, Republic of Albania \\ ${ }^{5}$ Department of Internal Medicine, Faculty of Medicine, Tetovo, Republic of North Macedonia \\ ${ }^{6}$ Department of Cardiology, Medical Center, Dures, Republic of Albania \\ ${ }^{7}$ Department of Cardiology, Medical Center, Dures, Republic of Albania \\ ${ }^{8}$ Private Health Institute of Family Medicine, "Florenc", Tetovo, Republic of North Macedonia \\ 'Department of Internal Medicine, General Hospital, "DR Ferit Murat" Gostivar, Republic of North Macedonia \\ ${ }^{10}$ Private Health Institute,"Rostusha" Debar, Republic of North Macedonia
}

\section{Abstract}

Background: An increasing body of evidence indicates that inflammatory activation profoundly impacts the electrophysiological properties of cardiomyocytes. A marker of systemic inflammation such as C-reactive protein(CRP), is associated with all parameters of the Mtabolic syndrome(MetS) and that may result in adverse cardiac events via multiple effects, ultimately resulting in a prolongation of Action Potential duration (APD), and thereby of the QTC (QT corrected) interval on ECG.

Objective: We sought to investigate the influence of CRP levels on the prevalence of prolonged QTdispersion and prolonged Tpeak-Tend -dispersion in the patients with MetS

Methods: We conducted a multicenter observational cross-sectional study. The study population consisted of 200 patients with MetS, stratified in two groups:103 participants (50 females and 53 males) with level of CRP $>3 \mathrm{mg} / \mathrm{l}$, and 97 participants ( 47 females and 50 males) with level of $C R P<3 \mathrm{mg} / \mathrm{l}$ ), who attended outpatient visits at general cardiology Health Care Clinics during 1 calendar year. For the analysis of the ECG, we performed a manual measurement of the values using a digital caliper with measuring range of $0-150 \mathrm{~mm}, 0.01 \mathrm{~mm}$ resolution, and 0-100 $\pm 0.02 \mathrm{~mm}$ accuracy. QT interval dispersion was obtained by the difference between the maximum and the minimum QT intervals found in the 12-lead electrocardiogram. The Tpeak-Tend interval was obtained from the difference between QT interval and $\mathrm{QT}_{\text {peak }}$ interval.

Results: Prolonged QTC. dispersion, was found in $51.4 \%$ of participants with level of CRP $>3 \mathrm{mg} / \mathrm{l}$ and in $32.9 \%$ of with level of $C R P<3 \mathrm{mg} / \mathrm{l}$, the differences were statistically significant. $(p=0.004)$. The results showed that $51.4 \%$ participants with level of CRP $>3 \mathrm{mg} / \mathrm{l}$ had a prolonged Tpeak-Tend interval, and $32.9 \%$ of participants with level of $C R P<3 \mathrm{mg} / \mathrm{I}$ had prolonged Tpeak-Tend interval. Difference were statistically significant. $(p=0.04)$. There were significant association of increased levels of CRP and QTC-dispersion (OR $=2.486,95 \% \mathrm{Cl} 1.389-4.446)$. There were significant association of increased levels of CRP with Tpeak-Tend Dispersion (OR=2.239,95\% Cl 1.262-3.976). Prolonged QTC max. Interval $\mathrm{OR}=2.236, \% \mathrm{Cl} 1.246-4.014)$,Prolonged Tp-Te-interval. (OR=2.367, $95 \% \mathrm{Cl} 1.327-4.222$ ), also there were significant association of increased levels of CRP with BMI. (OR=1.154, $95 \% \mathrm{Cl} 1.095-1.227)$ and significant association of increased levels of CRP with presence of uncontrolled glicemia.(OR=1.779, 95\% Cl 1.014-3.12).

Conclusion: We think we proved the hypothesis that patients with MetS and high level of CRP have higher prevalence of QT- dispersion and Tpeak-Tend dispersion than patients with MetS and lower level of CRP. These findings have both epidemiological and clinical relevance, also these findings might lend further insight into potential mechanisms by which MetS is associated with adverse cardiac events. 


\section{Introduction}

Metabolic syndrome (MetS) has been an increasing health problem worldwide for the last three decades. Estimates suggest that this disorder affects approximately 35\%$44 \%$ of the adult population. MetS is associated with adverse cardiac events [1,2].

Despite the increasing prevalence of MetS, we have a limited understanding of the contribution of metabolic abnormalities to adverse cardiac events, also precise mechanisms are still under study. An increasing body of evidence indicates that inflammatory activation profoundly impacts the electrophysiological properties of cardiomyocytes via multiple effects, ultimately resulting in a prolongation of Action Potential duration (APD), and thereby of the QTC (QT corrected interval) on ECG [3]. Chronic systemic inflammation in MetsS has emerged as a possible role in the development of arrhythimic events. A marker of systemic inflammation such as C-reactive protein (CRP), is associated with all parameters of the MS and that may result in arrhythmias [4-6].One interesting observation is that higher level of proinflamatory citokines in patients with MS correlate with sudden cardiac death [7]. QT interval remains the most widely used index for assessing the propensity to ventricular arrhythmias. Prolonged QT-dispersion, that reflects spatial inhomogeneity in ventricular repolarization, prolonged TpeakTend dispersion, that reflects transmural inhomogeneity in ventricular repolarization, are associated with increased risk of adverse cardiac events (certain arrhythmias and sudden cardiac death) [8,9]. We have e limited understanding of the contribution of chronic inflammation to changes in a set of electrophysiological parameters that indicate a prolonged and more heterogeneous repolarization in patient with MetS. We tested hypothesis: Patients with MS and high level of CRP have higher prevalence of QTdispersion and Tpeak-Tend dispersion than patients with MS and lower level of CRP. These findings might lend further insight into potential mechanisms by which MetS is associated with adverse cardiac events.

\section{Objective}

We sought to investigate the influence of CRP levels on the prevalence of prolonged QT-dispersion and prolonged Tpeak-Tend -dispersion in the patients with MS.

\section{Methods}

Study design

We conducted a multicenter observational cross-sectional study. The study population was recruited from our outpatient clinic between January 2018 and December 2018. Subjects who fulfilled the criteria for MetS according to the results of recent laboratory tests were prospectively evaluated.

The population consisted of 200 patients with MetS stratified in two groups: 103 participants (50 females and 53 males) with level of CRP $>3 \mathrm{mg} / \mathrm{l}$, and 97 participants (47 females and 50 males) with level of $\mathrm{CRP}<3 \mathrm{mg} / \mathrm{l}$ ).

All participants underwent a comprehensive medical history and physical examination. Resting ECG, anthropometrics, blood pressure (obtained after 10 min of rest in the sitting position, expressed as the average of 3 consecutive measurements). Hypertension was defined as a systolic blood pressure $\geq 140 \mathrm{mmHg}$, diastolic blood pressure $\geq 90 \mathrm{mmHg}$ and/or current anti-hypertensive therapy [10]. Diabetes mellitus was defined as a fasting serum glucose level $\geq 126 \mathrm{mg} / \mathrm{dL}$ and/or current medical therapy with an oral hypoglycemic agent and/or insulin [11]. Body mass index (BMI) was calculated as weight $(\mathrm{kg})$ divided by the square of the height $\left(\mathrm{m}^{2}\right)$. Weight was measured with weight balance scales, and height with stadiometer. WCi, was reported in $\mathrm{cm}$. An overnight fasting blood sample, was drawn from each patient to determine: blood glucose, lipid profile tests total serum cholesterol (TC), serum High density lipoproteins cholesterol (HDL-C), serum triglycerides (TG). The sample analysis was 
performed using standard biochemical analytical methods. Plasma CRP levels was measured using latex particle-enhanced immunoassay with the mephelometry (Roche Swiss).Consistent with recommendations from Centers for Disease Control and Prevention [12] (a CRP cutpoint of 3.0mg/L),was used to differentiate high-risk and low-risk group. We excluded all patients with: cardiac arrhythmias, left/right bundle branch block, pre-excitation syndromes, patients with pacemakers, and dialysis patients, anemia, electrolyte inbalnce, renal failure and pulmonary disease. We also excluded patients treated with drugs that prolong the QT interval, suggested by the European Society of Cardiology (ESC) [13].

MetS was defined according to the harmonized definition of the International Diabetes Federation and other organizations [1], that three or more out of five following criteria are considered as MetS: (1) central adiposity \{Waist circumference (WCi) $\}>102 \mathrm{~cm}$ in men and $>88 \mathrm{~cm}$ in women); (2) serum HDL-C $<50 \mathrm{mg} / \mathrm{dL}$ in women or $<40 \mathrm{mg} / \mathrm{dL}$ in men; (3) serum triglyceride levels $>150 \mathrm{mg} / \mathrm{dL}$; (4) SBP $\geq 130 \mathrm{mmHg}$ or DBP $\geq 85 \mathrm{mmHg}$ or use of antihypertensive drugs; (5) the presence of diabetes mellitus(DM) or use of anti-diabetic drugs.

\section{QTc-Dispersion. Tpeak-Tend disperion measurements}

All subjects underwent a standard 12-leads surface ECG. The ECG was always performed with the patient's supine, at rest, at a paper speed of $25 \mathrm{~mm} / \mathrm{s}$ and voltage of $10 \mathrm{~mm} / \mathrm{mV}$. To make the ECGs we used the electrocardiograph Cardioline - Delta 1 Plus. The subjects were required to have a normal ECG and with no pathologic processes that might affect ventricular repolarization. To this end, we conducted a consultation of the clinical process and only one ECG of the individuals that met the desired criteria. For the analysis of the ECG, we performed a manual measurement of the values using a digital caliper with measuring range of 0-150 $\mathrm{mm}, 0.01 \mathrm{~mm}$ resolution, and 0-100 \pm $0.02 \mathrm{~mm}$ accuracy. The value obtained was converted to milliseconds ( $\mathrm{ms}$ ).

Measurement of the QT interval (the interval from the start of the QRS complex to the end of the T-wave) was performed in all 12 leads, and the longest and the shortest intervals measured were selected. QT interval dispersion was obtained by the difference between the maximum and the minimum QT intervals found in the 12lead electrocardiogram. The QT interval was corrected according to Bazett's formula which consists in dividing the measured QT by the square root of the RR interval (QTC $=\mathrm{QT} / \sqrt{\mathrm{RR}}$ ), thus providing the $\mathrm{QT}$ interval value adjusted for heart rate.

The QTc dispersion was obtained by the difference between the highest and the lowest values of QTc in the 12 leads of the ECG [14].

According to internationally accepted guidelines, the QTC interval was considered prolonged when higher than $440 \mathrm{~ms}$ for male patients, and higher than $460 \mathrm{~ms}$ for female patients [15]. The QT dispersion was considered prolonged when higher than $65 \mathrm{~ms}$, according to other previously conducted studies [16]. Measurement of the Tpeak-Tend interval was conducted in DII, V2 and V5 leads. The Tpeak-Ted interval was obtained from the difference between QT interval and $\mathrm{QT}_{\text {peak }}$ interval. The Tpeak-Tend interval was considered prolonged when greater than $100 \mathrm{~ms}$, and the Tpeak-Tend dispersion was considered prolonged when higher than $20 \mathrm{~ms}$, as suggested by otherstudies [17]. The ECG was performed by the same operator, and the aforementioned measurements were made by two independent observers.In case of disagreement on the values obtained, the measurements were repeated by a third observer with expertise in electrocardiographic analysis.

The study is in compliance with the Declaration of Helsinki. All patient that participated in this study were written informed, consent was obtained from all participating patients before they were enrolled into the study (Figure 1). 


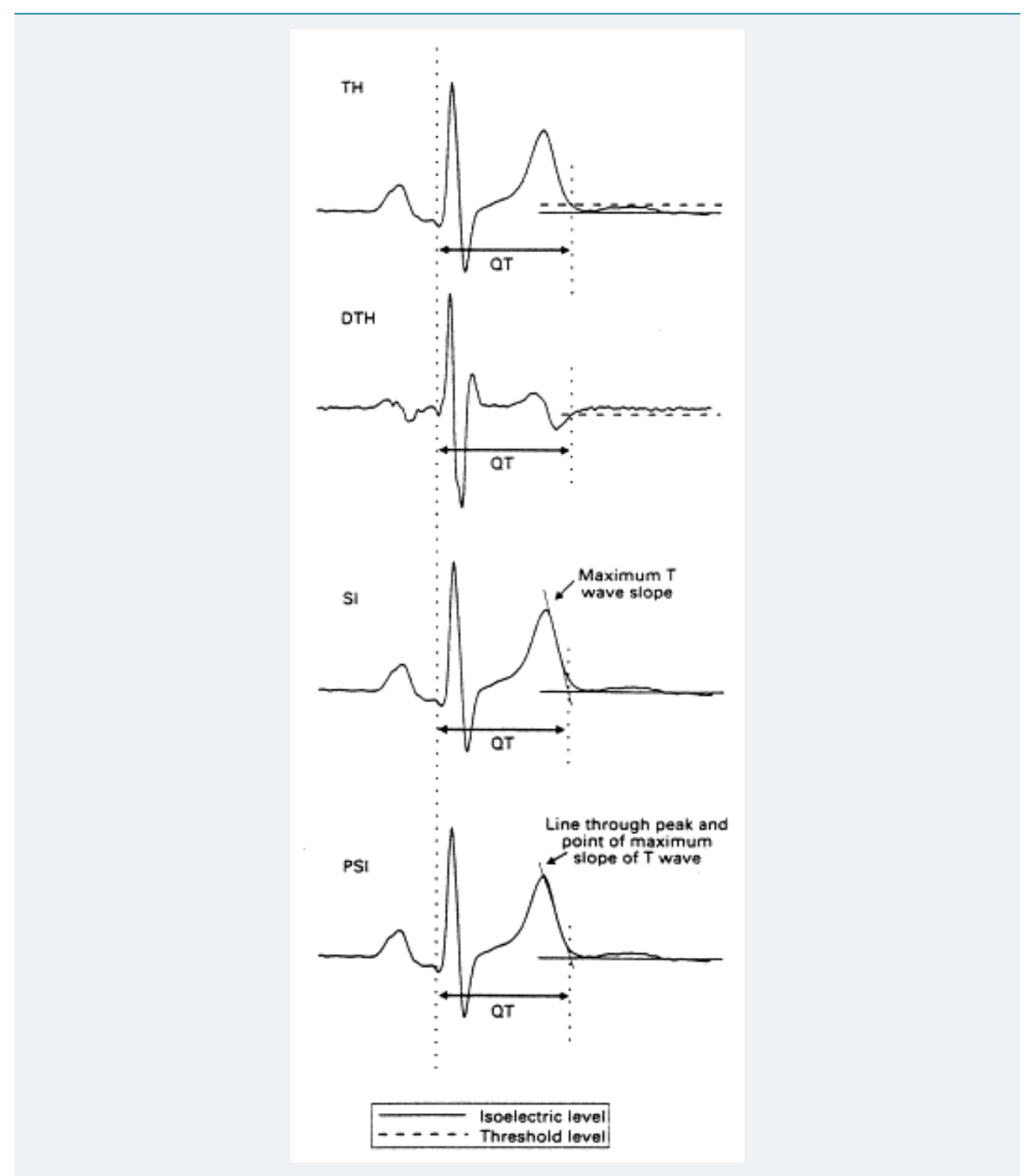

Figure 1: QT measurement techniques. From top to bottom: threshold method applied to the original T wave (TH), or to its differential (DTH), tangent method with a tangent to the steepest point of the descending limb of the T wave $(\mathrm{SI})$, tangent method with a line through the T wave peak and the maximum slope point (PSI).

\section{Statistical analysis}

Results are expressed as mean and $\pm \mathrm{SD}$, or as percentage. A simple descriptive analysis was performed for the general characterization of the sample and distribution of variables. The distribution of variables was tested for normality using the Kolmogorov-Smirnov test, and the heterogeneity of variances was evaluated by Levene's test. To compare baseline characteristics and echocardiographic findings between groups, we used Students unpaired $t$ test for continuous data, Mann-Whithey $\mathrm{U}$-test for continuous data with abnormal distribution, and $\mathrm{X}^{2}$-test for categorical data. The association between variables were analyzed using logistic regression. Odds ration (OR) and $95 \%$ confidence interval (CI) were estimated by logistic regression. A, $p$ value $<0.05$ was considered statistically significant for a confidence interval of $95 \%$.Statistical analyses were performed with the SPSS software package (SPSS 19.0).

\section{Results}

A total of 200 patients with MS stratified in two groups: 103 participants (50 females and 53 males) with level of CRP $>3 \mathrm{mg} / \mathrm{l}$, and 97 participants ( 47 females and 50 males) with level of $\mathrm{CRP}<3 \mathrm{mg} / \mathrm{l}$ ), completed the suvey and provided data for a onemedical record review. 
Baseline demographic, clinical, laboratory and electrocardiographic data are shown in table 1

There were no statistically significant differences in age between the participants with level of $\mathrm{CRP}>3 \mathrm{mg} / \mathrm{l}$ and participants with level of $\mathrm{CRP}<3 \mathrm{mg} / \mathrm{l}$ (mean age $55.4 \pm 6.3$ vs. $54.5 \pm 7,3 ; p=0.86$ ). No significant differences between the participants with level of $\mathrm{CRP}>3 \mathrm{mg} / \mathrm{l}$ and participants with level of $\mathrm{CRP}<3 \mathrm{mg} / \mathrm{l}$ were observed in relation to presence of : systolic and diastolic blood pressure $(86,5 \%$ vs.87,6\% p $=0.95 ; 86,5 \%$ vs.87,6\% p=0.95),T2DM(90\% vs. $89 \%$ p=0.9),WC ( $82 \%$ vs. $83 \%$ p=0.9),HDL(72\% vs.71\% p=0.9),Trig(63\% vs.60\% p=0.8), three risk factors(47\% vs.69\% p=0.09),four risk factors $(34 \% 23 \% \mathrm{p}=0.19)$.

Significant differences between groups were observed in relation to: BMI, was significantly higher in participants with level of CRP $>3 \mathrm{mg} / \mathrm{l}$ than participants with level of $\mathrm{CRP}<3 \mathrm{mg} / \mathrm{l}(30,4 \pm 3,9$ vs.25,3 $\pm 4,7 \mathrm{p}=0.00)$, glycemia level, was significantly higher in participants with level of CRP $>3 \mathrm{mg} / \mathrm{l}$ than participants with level of $\mathrm{CRP}<3 \mathrm{mg} / \mathrm{l}$ $(6,8 \pm 0,9$ vs. $6,5 \pm 0,8 \mathrm{p}=0.006)$.Number of risk factors, was significantly higher in participants with level of $\mathrm{CRP}>3 \mathrm{mg} / \mathrm{l}$ than participants with level of $\mathrm{CRP}<3 \mathrm{mg} / \mathrm{l}(17 \%$ vs. $0,7 \%$; $=0.01$ ).

We conducted a comparative analysis between the participants with level of $\mathrm{CRP}>3 \mathrm{mg} / \mathrm{l}$ and participants with level of $\mathrm{CRP}<3 \mathrm{mg} / \mathrm{l}$, of the following parameters: QT and QTC intervals, QT and QTC dispersions, Tpeak-Tend intervals, and Tpeak-Tend dispersions, data are shown in table 2.

QT and QTC intervals: The result showed that, only mean of QTCmax. Interval, was significantly higher in participants with level of CRP $>3 \mathrm{mg} / \mathrm{l}$ than participants with level of $\mathrm{CRP}<3 \mathrm{mg} / \mathrm{l}(448.27 \pm 16.2 \mathrm{~ms}$ vs.437.92 $\pm 15.2 \mathrm{~ms}, \mathrm{p}<0.001)$. No significant differences were observed between participants with level of CRP $>3 \mathrm{mg} / \mathrm{l}$ and participants with level of $\mathrm{CRP}<3 \mathrm{mg} / \mathrm{l}$, in others means QT. intervals and means of corrected for Heart rate QT. intervals. QT-max. (387.88 \pm 8.8 vs.389.34 $\pm 10.8, p=0.28$ ); QT-min. (357.18 \pm 3.9 vs.359.79 $\pm 5.8, \mathrm{p}=0.32)$; QT-mean (374.81 \pm 1.8 vs. 375.65 , $\mathrm{p}=0.68)$; QTC-min (385.08 \pm 12.5 vs $387.45 \pm 14.11$, $\mathrm{p}=0.64)$; QTC-mean $(412.97 \pm 11.2$ vs. $413.94 \pm 12.5, \mathrm{p}=0.55)$.

Prolonged (QT dispersion and QTC dispersion): No significant differences were observed between participants with level of CRP $>3 \mathrm{mg} / \mathrm{l}$ and participants with level of $\mathrm{CRP}<3 \mathrm{mg} / \mathrm{l}$ in relation to prolonged QT-dispersion $(29.39 \pm 2.2$ vs.30.42 \pm 1.8 ,

\begin{tabular}{|c|c|c|c|c|c|c|c|c|}
\hline \multirow{2}{*}{\multicolumn{2}{|c|}{ Variables }} & \multicolumn{3}{|c|}{$\begin{array}{c}\text { Gr.1 (CRP>3.0mg/L) } \\
(\mathrm{N} .107)\end{array}$} & \multicolumn{3}{|c|}{$\begin{array}{c}\text { Gr.2 (CRP<3.0mg/L) } \\
\text { (N.97) }\end{array}$} & \multirow[t]{2}{*}{ p-value } \\
\hline & & N. (\%) & Men & \pm SD & N. (\%) & Mean & \pm SD & \\
\hline \multirow[t]{2}{*}{ Gender } & Females & $46(47)$ & & & $48(46 \%)$ & & & 0.68 \\
\hline & Males & $51(53)$ & & & $55(54 \%)$ & & & 0.57 \\
\hline \multicolumn{2}{|c|}{ Age (year) } & & 55,4 & $\pm 6,3$ & & 54,5 & $\pm 7,3$ & 0.86 \\
\hline \multicolumn{2}{|c|}{$\mathrm{BMI}\left(\mathrm{kg} / \mathrm{m}^{2}\right)$} & & 30,4 & $\pm 3,9$ & & 25,3 & $\pm 4,7$ & $0.00 *$ \\
\hline \multicolumn{2}{|c|}{$\mathrm{SBP}(\mathrm{mmHg})$} & $90(86,5)$ & 124,5 & $\pm 15,6$ & $85(87,6)$ & 126,9 & $\pm 16,5$ & 0,38 \\
\hline \multicolumn{2}{|c|}{$\mathrm{DBP}(\mathrm{mmHg})$} & $90(86,5)$ & 80,9 & $\pm 4,5$ & $85(87,6)$ & 78,9 & $\pm 3,5$ & $0.01 *$ \\
\hline \multicolumn{2}{|c|}{ Glicemia(mmol/d) } & & 6,8 & $\pm 0,9$ & & 6,5 & \pm 0.8 & $0.006^{*}$ \\
\hline \multicolumn{2}{|c|}{ T2DM (N.\%) } & $93(90)$ & & & $87(89)$ & & & 0.9 \\
\hline \multicolumn{2}{|c|}{ WCi(cm.) } & $85(82)$ & & & $82(83)$ & & & 0.9 \\
\hline \multicolumn{2}{|c|}{$\mathrm{HDL}-\mathrm{chlol}(\mathrm{mmol} / \mathrm{l})$} & $75(72)$ & & & $69(71)$ & & & 0.9 \\
\hline \multicolumn{2}{|c|}{ Triglicer(mmol/l). } & $65(63)$ & & , & $59(60)$ & & X & 0.8 \\
\hline \multicolumn{2}{|c|}{$\mathrm{CRP}(\mathrm{mg} / \mathrm{L})$} & 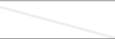 & 7,7 & $\pm 2,5$ & & 2.7 & \pm 0.1 & $0.00 *$ \\
\hline \multicolumn{2}{|c|}{ Three MetS riskfac. } & $48(47)$ & $x_{2}$ & & $67(69)$ & & & 0.09 \\
\hline \multicolumn{2}{|c|}{ Four MetS risk fac. } & $36(34)$ & & & $23(24)$ & & & 0.19 \\
\hline \multicolumn{2}{|c|}{ Five MetS risk fac. } & $18(17)$ & 8 & & $7(0,7)$ & & & $0.01 *$ \\
\hline \multicolumn{9}{|c|}{$\begin{array}{l}\text { Values are mean } \pm \text { SD;y=year; BMI:body mass index;SBP:systolic blood presure;DBP:diastolic blod presure; } \\
\text { T2DM:diabetes mellitus type 2presence ;serumHDL-C-high.density cholesterol;serum Triglicerides; } h \text { s-CRP:C-reative } \\
\text { protein;WC:weist circumference; NRF:number of riskfactor present(3-three,4-four,5-five). }\end{array}$} \\
\hline
\end{tabular}




\begin{tabular}{|c|c|c|c|c|c|}
\hline \multirow{3}{*}{ Variables } & \multicolumn{5}{|c|}{ Study Groups. (N.200) } \\
\hline & \multicolumn{2}{|c|}{$\begin{array}{c}\text { Gr.1 (CRP>3.0mg/L) } \\
(\mathrm{N} .103)\end{array}$} & \multicolumn{3}{|c|}{$\begin{array}{c}\text { Gr.2 (CRP< } 3.0 \mathrm{mg} / \mathrm{L}) \\
(\mathrm{N} .97)\end{array}$} \\
\hline & Mean & $\pm S D$ & Mean & $\pm S D$ & p-value \\
\hline QT-max.(mms) & 387,88 & 8,8 & 389,34 & 10,2 & 0.28 \\
\hline QT-min. & 357,18 & 3,9 & 359,79 & 5,8 & 0.32 \\
\hline QT-mean. & 374,81 & 1,8 & 375,65 & 5,5 & 0,68 \\
\hline QT-disp. & 29,36 & 2,2 & 30,42 & 1,8 & 0.65 \\
\hline QTC-max.(mms) & 448,27 & 16,2 & 437,92 & 15,5 & $0.001 *$ \\
\hline QTC-min. .(mms) & 385,08 & 12,5 & 387,45 & 14,11 & 0.64 \\
\hline QTC-mean. .(mms) & 412,97 & 11,2 & 413,94 & 12,5 & 0.55 \\
\hline QTC-disp. .(mms) & 44,37 & 21,8 & 37,15 & 18,1 & $0.01 *$ \\
\hline Tp-Te.II.(mms) & 69,41 & 7,7 & 70,16 & 5,6 & 0.58 \\
\hline Tp-Te.V2.(mms) & 70,82 & 4,8 & 69,95 & 5,6 & 0.67 \\
\hline Tp-Te.V5.(mms) & 82,05 & 7,6 & 78,51 & 6,3 & $0.001 *$ \\
\hline Tp-Te-disp. & 19,77 & 1,9 & 18,22 & 2,7 & $0.006^{*}$ \\
\hline
\end{tabular}

QT-max.=maximal interval; QTC maximal interval; QT-min=QT-miminal interval; QT-mean=QT-mean interval; QTdisp=QT-dispersion; QTC-mean=QTC-mean interval; QTC-min=QTC-min interval; QTC-d=QTC-dispersion; Tp-Te=Tpeak -Tend intervals in II,V2,V5-derivations;Tp-Te-disp=Tpeak-Tend dispersion.

$\mathrm{p}=0.65$ ). Significant differences between groups were observed in relation to prolonged QTC-dispersion. Participants with level of CRP $>3 \mathrm{mg} / \mathrm{l}$, have a significantly higher QTC dispersion than participants with level of CRP $<3 \mathrm{mg} / \mathrm{l} \quad(44,37 \pm 21.8$ vs.37.15 $\pm 18.1 . \mathrm{p}=0.01$ ).

Frequency of prolonged QTCmax. Interval: Prolonged QTC.max. interval, was found in $46.6 \%$ of participants with level of CRP $>3 \mathrm{mg} / \mathrm{l}$ and in $27.8 \%$ in participants with level of $\mathrm{CRP}<3 \mathrm{mg} / \mathrm{l}$, the differences were statistically significant. $(\mathrm{p}=0.04)$.

Frequency of prolonged QTC-dispersion: Prolonged QTC. dispersion, was found in $51.4 \%$ of participants with level of $\mathrm{CRP}>3 \mathrm{mg} / \mathrm{l}$ and in $32.9 \%$ of with level of $\mathrm{CRP}<3 \mathrm{mg} / \mathrm{l}$, the differences were statistically significant. $(\mathrm{p}=0.004)$.

Tpeak-Tend intervals: Regarding the comparison of Tpeak-Tend intervals prolongation, no significant differences were observed between participants with level of CRP $>3 \mathrm{mg} / \mathrm{l}$ and participants with level of CRP $<3 \mathrm{mg} / \mathrm{lin}$ any of the comparisons made. Mean Tpeak-Tend-intervals in: DII $(69.41 \pm 7.7$ vs.70.16 $\pm 5.6, p=0.58$; V2 $(70.82 \pm 4.8$ vs.69.95 $\pm 5.6, \mathrm{p}=0.67$. But the diference were statistically significante in V5 $(82.05 \pm 7.6$ vs. $78,51 \pm 6.3, \mathrm{p}=0.04)$.

Prolonged Tpeak-Tend Dispersion: Regarding the comparison of Dispersion of Tpeak-Tend intervals, in participants with level of CRP $>3 \mathrm{mg} / \mathrm{l}$ and in participants with level of $C R P<3 \mathrm{mg} / \mathrm{l}$, the results showed that participants with level of CRP $>3 \mathrm{mg} / \mathrm{l}$ have a significantly higher mean Tpeak-Tend dispersion than participants with level of CRP<3mg/l. (19.77 \pm 1.9 vs.18.22 $\pm 2.7, \mathrm{p}=0.006)$.

Frequency of prolonged Tpeak-Tend intervals: The results showed that $51.4 \%$ participants with level of CRP $>3 \mathrm{mg} / \mathrm{l}$ had a prolonged Tpeak-Tend interval, and $30.9 \%$ of participants with level of CRP $<3 \mathrm{mg} / \mathrm{l}$ had prolonged Tpeak-Tend interval. Difference were statistically significant $(\mathrm{p}=0.004)$.

Frequency of prolomged Tpeak-Tend Dispersion: The results showed that $51.4 \%$ participants with level of $\mathrm{CRP}>3 \mathrm{mg} / \mathrm{l}$ had a prolonged Tpeak-Tend interval, and $32.9 \%$ of participants with level of $\mathrm{CRP}<3 \mathrm{mg} / \mathrm{l}$ had prolonged Tpeak-Tend interval. Difference were statistically significant $(\mathrm{p}=0.04)$.

In a Simple logistic regression (Table 3), we investigated the independent association of CRP levels with: QTC-dispersion, Tp-Te-dispersion, Prolonged QTC max. interval, Prolonged Tp-Te-interval, BMI and uncontrolled glicemia. There were significant association of increased levels of CRP and QTC-dispersion (OR $=2.486,95 \%$ CI 1.389 - 
Table 3: Frequency of QTC-dispersion, Tp-Te dispersion and prolonged QTC maximal interval, Tp-Te interval of study population stratified by levels of CRP. (n-200).

\begin{tabular}{|c|c|c|c|}
\hline \multicolumn{2}{|c|}{ Study Groups.(N.200) } & \\
\hline VARIABLES & Gr.withCRP>3mg/L(N.103) & Gr.with CRP<3mg/L(N.97) & P \\
\hline Frequency of QTC-dispersion (No;\%) & $53(51,4)$ & $29(29,8)$ & $0.004^{\star}$ \\
\hline Frequency of Tp-Te-dispersion (No; $)$ & $53(51,4)$ & $32(32,9)$ & $0.004^{\star}$ \\
\hline Frequency of prolong.QTC.max.int. (No; $\%$ & $48(46,6)$ & $27(27,8)$ & $0.04^{*}$ \\
\hline Frequency of prolong. Tp-Te.int. (No;\%) & $53(51,4)$ & $30(30,9)$ & $0.004^{\star}$ \\
\hline
\end{tabular}

Prolong.QTC.max.int. =prolonged QTC maximal interval; Prolong.Tp-Te int=prolonged Tpeac-Tend interval. $P^{*}<0.05$ for between group cooperation.

4.446). There were significant association of increased levels of CRP with Tpeak-Tend Dispersion(OR=2.239,95\%CI 1.262-3.976). Prolonged QTC max. interval OR=2.236,\%CI 1.246-4.014),Prolonged Tp-Te-interval. (OR=2.367,95\%CI1.327-4.222), also there were significant association of increased levels of CRP with BMI.(OR=1.154,95\%CI 1.095-1.227) and significant association of increased levels of CRP with presence of uncontrolled glicemia.(OR=1.779, 95\%CI 1.014-3.12).

\section{Discusion}

Despite the increasing prevalence of MetS, we have a limited understanding of the contribution of metabolic abnormalities to adverse cardiac events. Increasing body of evidence indicates that inflammatory activation profoundly impacts the electrophysiological properties of cardiomyocites [3]).In this study we found that patients with MetS and higher levels of CRP had significantly higher prevalence set of electrophysiological parameters that indicate a prolonged and more heterogeneous repolarization than did those with MetS and lower levels of CRP. Results of present study confirmed our hypothesis. Experimental and observational evidence suggest that inflammation has a pivotal role in cardiac remodeling in patient with MetS [19], also several proinflamatory cytokines modulate membrane potencial and abnormal $\mathrm{Ca}^{2+}$ homeostasis with consequently prolongs the $\mathrm{Ca}^{2+}$ transient duration and action potencial [20]. Increased dispersion of repolarization between the base and apex of the heart intramurally or in the region of interventricular septum predisposes to ventricular arrhythmias, especially in the presence of ion channel diseases including long QT syndrome, short QT syndrome [21,22]. These markers may be used as an electrocardiographic index of ventricular arrhythmogenesis and sudden cardiac death [23]. In our study, prevalence of prolonged QTC-max. interval, prolonged QTCdisprsion and prolonged Tpek-Tend interval, prolonged Tpek-Tend-dispersion, was higher in patient with MetS and higher levels of CRP. Previous evidence suggest that MetS lead to cardiac electrical remodeling [24], and increased levels of CRP was found to be associated with severity of Mets [25]. In present study increased levels of CRP, was associated independently with number of risk factor of MetS. Others have found similar results $[25,26]$. A number of previous studies have demonstrated that CRP levels correspond with individual components of MetS $[27,28]$. In present study increased levels of CRP, was associated independently with Obesity, BMI, uncontrolled glicemia and uncontrolled BP. Results they are consistent with prior studies [27-30]. Another fact of great importance is the influence of medication on several elektrocardiographic parameters, there are numerous drugs that cause prolongation and/or dispersion of repolarization. This study was excluded individuals receiving medication that are more frequently associated with repolarization changes, however, there was no absolute guarantee that all other medications had no influence on repolarization. In fact, a study by Costa et al. [31], evaluated the influence of metformin (a drug commonly used in diabetics to control blood glucose) on QT interval and QT dispersion in diabetic rats. The results showed that, with low and moderate doses of metformin, there were 
significant changes in electrcardiographic parameters, but this did not happen when the dose was high. Our data highlights the possible role of chronic inflammation in the development of electrical remodeling in patients with MetS.

Several limitations deserve mention: Our study is a cross-sectional observational study, oversimplification of multifactorial mechanisms based upon limited markers, is inhered to this kind of studies and precludes causal inferences. A larger sample would certainly increase the statistical power of the study, and probably some differences would therefore become more expressive. Moreover, manual measurements of intervals without the support of any technology that could ensure a more precise measurements may also be an aspect to be taken into account. The accuracy and reproducibility of measurements of repolarization parameters problem encountered was the lack of a consensus on the values of several normal electrocardiographic parameters. Despite some methodological limitations, this study clearly demonstrated a relationship between increased levels of CRP and changes in set of electrophysiological parameters that indicate a prolonged and more heterogeneous repolarization in patient with MetS.

\section{Conclusion}

We think we proved the hypothesis that patients with MetS and high level of CRP have higher prevalence of QT- dispersion and Tpeak-Tend dispersion than patients with MetS and lower level of CRP. These findings have both epidemiological and clinical relevance, also these findings might lend further insight into potential mechanisms by which MetS is associated with adverse cardiac events. Assessment of levels of CRP for arrhythmogenic risk may be important for better risk stratification of patients with MetS, a conclusion that needs confirmation in larger prospective studies.

Materials-Agim Zeqiri; Dali Lala, Fatmir Ferati; Arben Mirto; Data collection/ processing-Sotiraq Xhunga; Artur Serani; Ylber Jani; Analysis/interpretation-Ylber Jani; Ahmet Kamberi; Atila Rexhepi; Bekim Pocesta; Literature Search- Ylber Jani; Agin Zeqiri; Dali Lala; Fatmir Ferati; Artur Serani. Critical Reviews-Ahmet Kamberi.

\section{Acknowledgment}

We thank Ahmet Kamberi PhD, Atila Rexhepi PhD; Bekim Pocesta MD; Dali Lala MD; Fatmir Ferati PhD; Zeqiri Agim MD; Mirto Arben MD, for their contributions to this study.

\section{References}

1. Ford ES. Prevalence of the Metabolic Syndrome Defined by the International Diabetes Federation among adults in the U.S. Diabetes Care. 2005; 28: 2745-2749. Ref.: http://bit.ly/2FzEopG

2. Ford ES, Li C, Zhao G. Prevalence and correlates of metabolic syndrome based on a harmonious definition among adults in the US. J Diabetes. 2010; 2: 180-193. Ref.: http://bit.ly/2ZUG3xN

3. Pietro EL, Pier LC, Franco LP. Long QT Syndrome: An Emerging Role for Inflammation and Immunity. Front Cardiovasc Med. 2015; 2: 26. Ref.: http://bit.ly/2LmDBMF

4. Evaristo FS, Alejandro TQ, Christian SP, Noemi GB, Cicero W, et al. Proinflamatory cytocines are soluble mediators linked with ventricular arrhythmias and contractile dysfunction in a rats model of metabolic syndrome. Oxid Med Cell Longev. 2017; 2017: 7682569. Ref.: http://bit.ly/2XE8DGc

5. Watanabe $\mathrm{H}$, Tanabe $\mathrm{N}$, Watanabe $\mathrm{T}$, Darbar $\mathrm{D}$, Roden DM, et al. Metabolic syndrome and risk of development of atrial fibrillation: the Niigata Preventive Medicine Study. Circulation. 2008; 117: 1255-1260. Ref.: http://bit.ly/2Nh8hRW

6. Ridker PM, Buring JE, Cook NR, Rifai N. C-reactive protein, the metabolic syndrome, and risk of incident cardiovascular events: an 8-year follow-up of 14719 initially healthy American women. Circulation. 2003; 107: 391-397. Ref.: http://bit.ly/2Lu4OwO

7. Hussein AA, Gottdiener JS, Bartz TM, Sotoodehnia N, DeFilippi C, et al. Inflammation and sudden cardiac death in a community-based population of older adults: the cardiovascular health study. Heart Rhythm. 2013; 10: 1425-1432. Ref.: http://bit.ly/2FEKYvo 
8. Elming $H$, Holm E, Jun L Torp-Pedersen C, Køber L, Kircshoff M, et al. The prognostic value of the QT interval and QT interval dispersion in all-cause and cardiac mortality and morbidity in population of Danish citizens. Eur Heart J.1998; 19: 1391-400. Ref.: http://bit.ly/2Ln3Get

9. Fukuda K, Fukuda Y, Salles GF, Cardoso CR. Prolonged QT-intreval and QT-dispersion, are risk marker of arrhythmias and sudden cardiac death. Hypertens. 2009; 11: 231-237.

10. The seventh report of Join National Committee on Prevention, Detection, Evaluation and treatment of High Blood Pressure. JAMA 2003; 289: 2550-2572. Ref.: http://bit.ly/2ITItaC

11. America Diabetes Association. Standards for medical care for patient with diabetes mellitus Diabetes Care. 2002; 25 (Suppl 1): S33-S49. Ref.: http://bit.ly/2ZSiYMw

12. Center for disease control/American Heart association Workshop on inflammatory Markers, and Cardiovascular Disease: Application to clinical and public health practice: Atalanta, March 14-15, 2002. Atlanta, Ga. Centers for Disease Control and Prevention: 2002.

13. Haverkamp W, Breithardt G, Camm AJ, Janse MJ, Rosen MR, et al. The potential for QT prolongation and proarrhythmia by non-antiarrhythmic drugs: clinical and regulatory implications. Report on a policy conference of the European Society of Cardiology. Eur Heart J. 2000; 21: 1216-1231. Ref.: http://bit.ly/2Xe4lpK

14. Chiladakis $\mathrm{J}$, Kalogeropoulos A, Arvanitis $\mathrm{P}$, Koutsogiannis N, Zagli F, et al. Heart rate-dependence of QTc intervals assessed by different correction methods in patients with normal or prolonged repolarization. Pacing Clin Electrophysiol. 2009; 33: 553-560. Ref.: http://bit.ly/2XaM7FR

15. Corrado D, Pelliccia A, Bjornstad HH, Vanhees L, Biffi A, et al. Cardiovascular pre-participation screening of young competitive athletes for prevention of sudden death: proposal for a common European protocol. Consensus Statement of the Study Group of Sport Cardiology of the Working Group of Cardiac Rehabilitation and Exercise Physiology and the Working Group of Myocardial and Pericardial Diseases of the European Society of Cardiology. Eur Heart J. 2005; 26: 516-524. Ref.: http://bit.ly/2Ln4501

16. Salles GF, Deccache W, Cardoso CR. Usefulness of QT-interval parameters for cardiovascular risk stratification in type 2 diabetic patients with arterial hypertension. J Hum Hypertens. 2005; 19: 241249. Ref.: http://bit.ly/2X1s6wo

17. Castro Hevia J, Antzelevitch C, Tornes Barzaga F, Dorantes Sanchez M, Dorticos Balea F, et al. TpeakTend and Tpeak- Tend dispersion as risk factors for ventricular tachycardia/ventricular fibrillation in patients with the Brugada syndrome. J Am Coll Cardiol. 2006; 47: 1828-1834. Ref.: http://bit. ly/2RAR3xs

18. Hussein AA, Gottdiener JS, Bartz TM, Sotoodehnia N, DeFilippi C, et al. Inflammation and sudden cardiac death in community-based population of older adults: the cardiovascular health study. Heart Rhythm. 2013; 10: 1425-1432. Ref.: http://bit.ly/2FEKYvo

19. Rocha VZ, Libby P. Obesity, inflammation and atherosclerosis. Nat Rew Cardiol. 2009; 6: 399-409. Ref.: http://bit.ly/2ZXw8YB

20. Duncant DJ, Yang Z, Hopkins PM, Steele DS, Harison SM. TNF-a,IL-1 $\beta$ increase $\mathrm{Ca}^{2+}$ leak from the sarcoplamic reticulum and susceptibility to arrhythmias in rat ventricular myocites. Cell calcium. 2010; 47: 378-386. Ref.: http://bit.ly/2YgjHGP

21. Bieganowska K, Sawicka-Parobczyk M, Bieganowski M, et al. Tpeak-tend interval in 12-lead electrocardiogram of healthy children and adolescent's tpeak -tend interval in childhood. Ann Noninvasive Electrocardiol. 2013; 18: 344-351. Ref.: http://bit.ly/2IQA73b

22. Letsas KP, Weber R, Astheimer K, Kalusche D, Arentz T. Tpeak-Tend interval and Tpeak-Tend/ QT ratio as markers of ventricular tachycardia inducibility in subjects with Brugada ECG phenotype. Europace. 2010; 12: 271-274. Ref.: http://bit.ly/2xjfaY4

23. Castro Hevia J, Antzelevitch C, Tornés Bárzaga F, Sánchez MD, Balea FD, et al. Tpeak-Tend and Tpeak-Tend dispersion as risk factors for ventricular tachycardia/ventricular fibrillation in patients with the Brugada syndrome. J Am Coll Cardiol. 2006; 47: 1828-1834. Ref.: http://bit.ly/2RAR3xs

24. Ylmaz H, Ozcan KS, Sayar N, Kemaloglu T, Gungor B, Erer B, et al. Metabolic syndrome is associated with atrial electrical and mechanical dysfunction. Med Princ Pract. 2015; 24: 147-152. Ref.: http://bit.ly/2ZPiUwP

25. Karakas MF, Buyukkaya E, Kurt M, Motor S, Akcay AB, Karakas E, et al. Serum pentraxin-3 levels are associated with the severity of metabolic syndrome. Med Princ Pract. 2013; 22; 274-279. Ref.: http://bit.ly/2REAwc8

26. Karaagac K, Emul A, Tenekecioglu E, Agca FV, Ozluk OA, et al. The Effects of Metabolic Syndrome on 
TpTe Interval and TpTe/QT Ratio in Patients with Normal Coronary Arteries. Eurasian J Med. 2014; 46: 182-186. Ref.: http://bit.ly/2KGLZXY

27. Paul MR, Julie EB, Nancy RC, Nader R. C-Reactive Protein, the Metabolic Syndrome, and Risk of Incident Cardiovasular Events. Circulation. 2003; 107: 391-397. Ref.: http://bit.ly/2LoMmGb

28. Masugata H, Senda S, Inukai M, Murao K, Tada S, et al. Association between hih-sensitivity C-reactive protein and left ventricular diastolic function assessed by echocardiography in patients with cardiovascular risk factors. J Exp Med. 2011; 223: 263-268. Ref.: http://bit.ly/2X8RMfs

29. Jani Y, Rexhepi A, Pocesta B, Xhunga S, Serani A, et al. Influence of C-Reactive Protein and Metabolic Syndrome on the Prevalence of Subclinical Left Ventricular Diastolic Dysfunction. American $\mathrm{J}$ Epidemiol Public Health. 2018; 2: 027-030. Ref.: http://bit.ly/2ITbiUz

30. Suis B, Heuten S, De Wolf D, Verherstraeten M, deBeck LO, et al. Glycemia and corrected QT Interval Prolongation in jung Type-1 diabetic patients: What is the relation? Diabetes Care. 2006; 29: 427-429. Ref.: http://bit.ly/2XAbb8h

31. Costa EC, Conclaves AA, Areas MA, Morgabel RG. Effects of Metformin on QTc interval dispersion of Diabetics rats. Arquivos de Cardiologia. 2008; 90: 232-238. Ref.: http://bit.ly/2XEdyql 